\title{
BMJ Global Health Finding the facts in an infodemic: framing effective COVID-19 messages to connect people to authoritative content
}

Andrew B Pattison, ${ }^{1}$ Monta Reinfelde, ${ }^{1}$ Hyunsoo Chang, ${ }^{2}$ Mayukh Chowdhury, ${ }^{2}$ Emma Cohen, ${ }^{2}$ Sean Malahy, ${ }^{2}$ Katie O'Connor, ${ }^{2}$ Mehdi Sellami, ${ }^{2}$ Karen L Smith, ${ }^{2}$ Charlotte Y Stanton, ${ }^{2}$ Bram Voets, ${ }^{2}$ Henry G Wei ${ }^{2}$

To cite: Pattison $A B$, Reinfelde $\mathrm{M}$, Chang $\mathrm{H}$, et al. Finding the facts in an infodemic: framing effective COVID-19 messages to connect people to authoritative content. BMJ Global Health 2022;7:e007582. doi:10.1136/ bmjgh-2021-007582

Handling editor Seye Abimbola

Received 29 September 2021 Accepted 22 December 2021

Check for updates

(C) Author(s) (or their employer(s)) 2022. Re-use permitted under CC BY-NC. No commercial re-use. See rights and permissions. Published by BMJ

${ }^{1}$ Digital Health and Innovation, World Health Organization, Geneve, Switzerland

${ }^{2}$ Google, Mountain View, California, USA

Correspondence to Andrew B Pattison; pattisona@who.int

\section{ABSTRACT}

The public's need for timely and trusted COVID-19 information remains high. Governments and global health agencies such as the WHO have sought to disseminate accurate and timely information to counteract misinformation and disinformation that has arisen as part of an 'infodemic' - the overabundance of information on COVID-19—some accurate and some not. In early 2020, WHO began a collaboration with Google to run online public service announcements on COVID-19, in the form of search ads displayed above results of Google Search queries. Web-based text ads can drive online searchers of COVID-19 information to authoritative COVID-19 content but determining what message is most effective is a challenge. WHO wanted to understand which message framing, that is, the way in which ad information is worded for the public, leads searchers to click through to WHO content. WHO tested 71 text ads in English across four COVID-19 topics using a mix of message frames: descriptive, collective, gain, loss, appeals to values and emphasising reasons. Between 11 September 2020 and 23 November 2020, there were 13 million views of the experimental WHO text ads leading to 1.4 million clickthroughs to the WHO website. Within the set of 71 ads, there was a large spread between the most effective and least effective messages; for messages on COVID-19, the best performing framings were more than twice as effective as the worst performing framings $(18.7 \%$ vs $8.5 \%$ engagement rate). Health practitioners can apply the messaging tactics WHO found to be successful to rapidly optimise messages for their own public health campaigns and better reach the public with authoritative information. Similar collaboration between big technology companies and governments and global health agencies has the potential to advance public health.

\section{INTRODUCTION}

The public's need for timely and trusted COVID-19 information remains high as cases are still rising in many parts of the world and there is continuing interest in COVID-19related topics such as COVID-19 vaccines. ${ }^{1}$
Summary box

The public's need for timely and trusted COVID-19 information remains high, especially as the COVID-19 outbreak and response has been accompanied by an 'infodemic' - the overabundance of information on COVID-19-some accurate and some not.

- Web-based text ads on Google Search provide an opportunity to help users find WHO content on COVID-19 but determining an effective messaging is a challenge.

- Optimising message framing in English language text ads informed by behavioural science was shown to be an effective mechanism for connecting millions of users to WHO content.

- There was a large spread between the message frames that engaged users more and those that did not. For messages on COVID-19, the best performing framings were more than twice as effective as the worst performing framings $(18.7 \%$ vs $8.5 \%$ engagement rate)

- National and global health practitioners may be able to apply the message tactics WHO found to be successful to rapidly test and optimise messages for more successful public health campaigns and better reach the public with trustworthy information.

For example, in 2020, COVID-19 was the most searched for topic globally, and the search volume for the term 'coronavirus vaccine' increased by $380 \%$ between December 2020 and its peak in August 2021. ${ }^{2}$

The COVID-19 pandemic and response have been accompanied by an 'infodemic'. This is an overabundance of information on COVID-19—some accurate and some not-which makes it hard for people to find trustworthy sources and reliable guidance when they need it. Given the extraordinary demand for information, governments and global health agencies such as the WHO have 
sought to disseminate accurate and timely information to counteract misinformation and disinformation. As part of its approach to disseminate facts and address misinformation, in early 2020, WHO began a collaboration with Google to boost public engagement with WHO's COVID-19 web content via public service announcements on Google Search. ${ }^{5}$

The internet offers an opportunity to move beyond historical public health campaign tools, such as posters, public service announcements and billboards, to webbased tools that can better target public health information. WHO, therefore, viewed Google Search ads as an opportunity to reach millions more people with authoritative content about COVID-19. Google provided probono ad grants for WHO to run online public health campaigns, in the form of text ads. Text ads are advertisements that appear on a Google Search results page coupled with a clickable link to the 'advertiser's' site. For instance, users searching for 'COVID-19' or related terms on Google Search engine could see text ads from WHO as top results, giving WHO the ability to reach a larger population.

Historically, the wording of public health advertisements has been determined by intuition about what language might be most compelling, often without supporting data. ${ }^{6}$ The evidence base is still growing on the most effective message framing for public health campaigns, and several systematic and rapid reviews of health message framing on a variety of health topics emphasise the need for clear, repeated, action-oriented messaging from a trusted source. ${ }^{7-10}$ Positive and gainframed messages that emphasise a collective or social responsibility message, versus an individual approach and loss-framed approach, may also be more effective for influencing health behaviours. The evidence, however, is mixed. $^{7-10}$

Further, determining what messaging appeals to which groups of people remains critical. ${ }^{11}$ For example, a review of vaccine communication found participant characteristics could be moderators of the effect of goal-framed versus loss-framed messaging (eg, perceived risk or loss), but again findings are inconsistent. ${ }^{12}$ The existing literature does reinforce, however, that adaptation is needed to fit local contexts. ${ }^{13} 14$ Health messaging should be tailored to reflect the range of influences and drivers of behaviour which may differ across target audiences, based on, for example, gender, age and sociocultural context. $^{12}{ }^{15}$ Stakeholder engagement is also important in identifying the most appropriate message framing and medium of message delivery. ${ }^{7}$

Given the unprecedented scale of the COVID-19 pandemic and influence of social media, previous findings may not directly apply. ${ }^{7}$ Yet, recent studies of COVID-19 health promotion campaigns have shown that positive framing or messaging that promotes collective responsibility and those noting personal health risks may increase people's intention to change or adopt behaviours, such as frequent handwashing or social distancing. ${ }^{16-18}$ These studies are reinforced by others that have promoted a series of strategies and principles based on behavioural science, social marketing and consumer research to inform communication interventions to promote whole population COVID-19 measures, including to motivate social distancing and improve vaccination uptake. ${ }^{19-21}$

Much of the current evidence describes framing for entire health promotion campaigns, which may differ from trying to direct people to authoritative content. However, informed by this broader context of work, we describe the development of a large-scale digital message optimisation experiment designed to increase traffic to WHO website content. We highlight the findings of the experiment and the learnings for future practice.

\section{WHO COVID-19 GLOBAL AD CAMPAIGN}

In March 2020, Google announced US\$250 million in ad grants to help WHO and over 100 government entities globally spread critical, accurate information on how to prevent the spread of COVID-19 and other measures to help local communities and individuals make better health decisions. ${ }^{5}$ Text ads on Google are limited to three 30-character headline messages and two brief 90-character descriptions. They are a common part of the experience of the millions of users who search on Google every day. Google text ads appear only when users enter specific related search keywords. The Ads system provides advertisers with standardised, aggregated and anonymised measurement of how many times each ad has been seen ('impressions') and clicked on ('clicks').

In April 2020, three months after declaring COVID-19 a Public Health Emergency of International Concern (PHEIC), WHO commenced its ad campaign on Google Search to raise credible content and counter misinformation on COVID-19-related information. At the time, the pandemic was in the early stage, and it was unclear when a COVID-19 vaccine might become publicly available. The early headline messages had a particular emphasis on providing generic information on COVID-19 (eg, 'COVID-19 Worldwide Dashboard-WHO Live World Statistics') and combating dangerous misinformation (eg, 'Can masks protect against the new Coronavirus infection?') that was spreading quickly, often leading to dire health consequences and hindering public health response. ${ }^{22-24}$ WHO was aware of public interest in disinformation and misinformation around COVID-19 vaccines, as the antivaccination movement had gained momentum during the pandemic. For example, in May 2020, a Pew Research poll found only around $40 \%$ of US adults said they would definitely get a COVID-19 vaccine if it were available. ${ }^{25}$ This suggested there was further opportunity to improve messaging, with a focus on vaccine acceptance, combating misinformation and connecting more users to WHO authoritative COVID-19related content. 
Table 1 Examples of different headline message framing

\begin{tabular}{|c|c|c|}
\hline Message framing & Description of framing & Examples of headline message \\
\hline Descriptive frame & $\begin{array}{l}\text { Highlights the information that is found on the } \\
\text { site }\end{array}$ & $\begin{array}{l}\text { WHO Official Updates } \\
\text { Symptoms of COVID-19 }\end{array}$ \\
\hline Collective frame & Highlights the actions of others & $\begin{array}{l}\text { Join your community } \\
\text { Millions wear masks }\end{array}$ \\
\hline Gain frame & Highlights positive outcomes & $\begin{array}{l}\text { Stay safe } \\
\text { Keep the spread low }\end{array}$ \\
\hline Loss frame & Highlights potential losses & $\begin{array}{l}\text { Don't risk your safety } \\
\text { Don't miss the latest }\end{array}$ \\
\hline Appeals to values & $\begin{array}{l}\text { Highlight personal values such as protecting } \\
\text { others and exercising personal choice }\end{array}$ & $\begin{array}{l}\text { Protect each other } \\
\text { Heroes wear masks }\end{array}$ \\
\hline Emphasising reasons & Highlights that there are reasons supporting & $\begin{array}{l}\text { Learn why vaccines work } \\
\text { See what you can do }\end{array}$ \\
\hline
\end{tabular}

\section{WHAT WE DID}

To increase engagement with WHO content on COVID19, we-a multidisciplinary team of public health, behavioural economics, medical, advertising and digital marketing experts at WHO and Google-designed 71 new text ads (ie, experimental ads). The text ads covered four COVID-19 topics: COVID-19 general; COVID-19 vaccines; vaccines general; and masks. For each topic, up to three 30-character headline messages were created in English using one of several frames: descriptive, collective, gain, loss, appeals to values and emphasising reasons (see table 1). These frames were selected based on the behavioural science academic literature regarding effective health messaging, ${ }^{96}$ and our various domain expertise. The aim was to understand which message framings appeal to the searcher and lead to a higher click-through to WHO content (see online supplemental figure $1)$. Given the urgent demand for information about COVID-19 and the increasing need to connect people to authoritative content, we did not undertake user testing during development of the messages.

The 71 text ads were loaded into the Google Ads system to show to Google users worldwide who were searching for COVID-19-related information in English. The ads ran from 11 September 2020 until 23 November 2020. The experimental ads did not change during this period. While these ads were running, WHO was also running existing, non-experimental ads. Ads were triggered by specific search terms, which were consistent across all experimental ads on the same topic (see online supplemental table 1 for common searches that could lead to these ads being shown). Which ad was shown to the user was determined by Google's automated Ads system. When a user clicked on an ad link, they were taken to relevant, associated content on the WHO website. To measure user engagement with WHO ads, a click-through rate (CTR), defined as total clicks ('clicks') that an ad received divided by the total number of times that the ad was shown ('impressions'), was calculated as the primary impact measure. For search ads, the system reports only total impressions and does not report unique impressions-meaning that the same user may have seen an ad more than once. This ad metric can also be broken down by country and certain inferred demographic factors (eg, gender, age), which are available to all Google Ads advertisers. According to Google documentation, ${ }^{27}$ when people are signed into their Google account, certain demographics may be inferred from their settings or activity on Google properties, depending on their account status. The data provided by the Ads system are anonymised and aggregated and cannot be traced back to individuals. The CTR was compared between frame types and across individual headlines to identify high and low-performing messages (see online supplemental table 2 for statistical details).

\section{WHAT WE FOUND}

Between 11 September 2020 and 23 November 2020, there were 13 million views of the experimental WHO text ads in English and 1.4 million click-throughs to the WHO website. India had the largest number of impressions (2.34 million) and clicks (245 744), followed by the UK, USA, Canada, the Philippines and Australia. The CTR varied across countries, reaching close to and exceeding $25 \%$ in some cases (eg, Lithuania, Malta and Uganda) and as low as 5\%-8\% in other countries, such as Argentina and the USA (see online supplemental table 3 for CTR across all available countries). From the inferred demographic factors, we found that males across all age groups had the highest number of impressions (which may reflect the global internet user gap with more men using the internet) ${ }^{28}$; a CTR between $11 \%$ and $13 \%$ was similar across genders and age groups (table 2). The 25-34 and 35-44year age groups had the highest number of impressions and click-throughs to the WHO website.

Within the set of 71 ads there was a large spread between the most effective and least effective messages and frames. Across all message frames, descriptive frames had the highest or second highest overall CTR (table 3), all of which were statistically significantly higher than the average CTR (see online supplemental table 2). The 


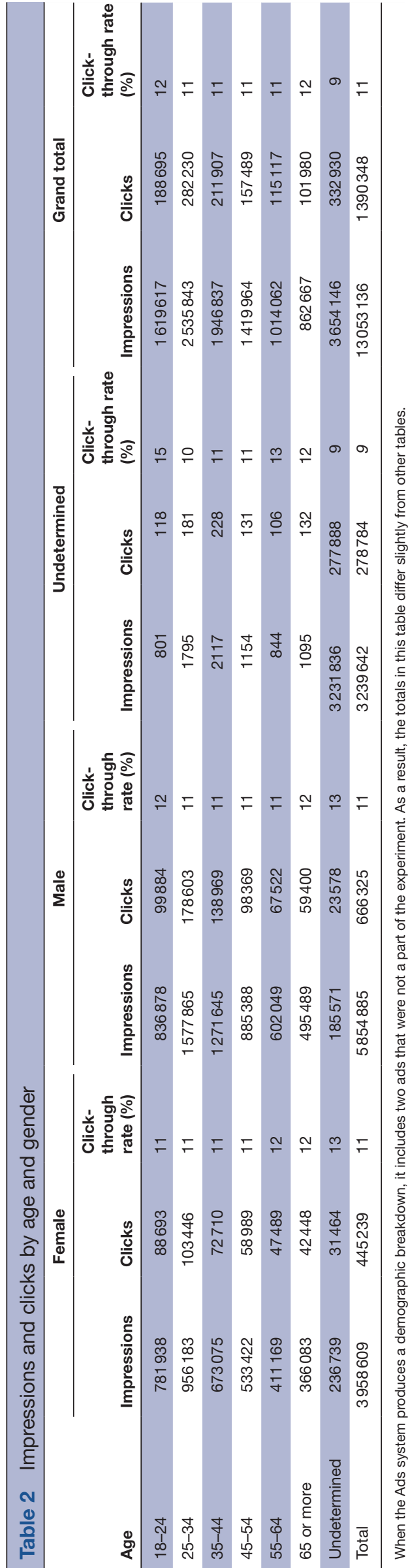

headline that was clicked on at the highest rate was 'WHO Official Updates: Coronavirus Disease 2020' (table 4). Other ads across the four topics with high CTRs included descriptive framing such as 'updates', 'information', 'current status', 'symptoms' and 'latest'. These keywords were also frequently searched for and may have matched the information that users were seeking.

Although descriptive framing performed best across all topics overall, messages that highlighted a positive outcome (ie, gain frame), such as staying informed and keeping the spread low, tended to perform well for general COVID-19, general vaccination and mask topics. Messages that highlighted potential losses tended to perform poorly. For example, the three gain-framed messages were in the top five performing mask ads, while the three loss-framed messages fell in the bottom $50 \%$ of mask ads. On average, across all four topics, gain frame had a higher CTR than loss frame.

\section{WHAT WE LEARNT}

Our work demonstrates that testing message framing in targeted online search ads can be used to identify messages that can connect large numbers of users to WHO content. We also showed that it is technically possible to launch an online campaign during an infodemic that can bring more people into contact with trustworthy content. Increasing access to WHO's authoritative content via Google Ads has helped to fill an information gap in countries in the absence of reliable and readily accessible public information. ${ }^{29}$

After this experiment ended, the top-performing ads were rolled out across other WHO ad campaigns to further increase traffic to the WHO website. In addition to removing the lowest performing ads, additional permutations of highperforming messages were added, and ads were expanded to Spanish, French, Portuguese, Russian and Chinese. Anecdotally, WHO saw an increase of approximately 1.6 million visitors to their website each month as a result of this work. These findings have also informed the message framing of other WHO product headlines, such as its weekly electronic newsletters.

Interestingly, we found that descriptive framing of information often led to higher engagement than other message framings. We suspect that this may be unique to contexts where individuals are actively searching for specific information. As opposed to other types of framing that we examined, descriptive framing may make it easy for users to determine if the hyperlinked information is relevant to their search query, and if so click on it. For example, if a user is searching for recent information on the COVID-19 pandemic, then 'WHO Official Updates' may more clearly communicate that the hyperlinked page contains the information that they are looking for than does 'Don't miss new updates'. Whether descriptive framing works well in other online contexts, such as social media, should be explored in future work.

Recent research suggests that, although many messaging strategies may be effective across many different countries, 


\begin{tabular}{|c|c|c|c|c|}
\hline Topic & Framing & Clicks & Impressions & Click-through rate (\%) \\
\hline \multirow[t]{6}{*}{ COVID-19 general } & Descriptive & 85507 & 458398 & 18.7 \\
\hline & Gain & 28338 & 217450 & 13.0 \\
\hline & Collective & 5266 & 49716 & 10.6 \\
\hline & Emphasising reasons & 3360 & 33677 & 10.0 \\
\hline & Appeals to values & 3797 & 40920 & 9.3 \\
\hline & Loss & 1562 & 18433 & 8.5 \\
\hline \multirow[t]{6}{*}{ Masks } & Descriptive & 7752 & 70062 & 11.1 \\
\hline & Gain & 1606 & 14918 & 10.8 \\
\hline & Appeals to values & 6763 & 67524 & 10.0 \\
\hline & Collective & 5047 & 60575 & 8.3 \\
\hline & Loss & 2836 & 42554 & 6.7 \\
\hline & Emphasising reasons & 2219 & 54792 & 4.1 \\
\hline \multirow[t]{6}{*}{ COVID-19 vaccines } & Descriptive & 649939 & 4306302 & 15.1 \\
\hline & Collective & 61583 & 434462 & 14.2 \\
\hline & Emphasising reasons & 28490 & 223574 & 12.7 \\
\hline & Gain & 16431 & 159609 & 10.3 \\
\hline & Loss & 30174 & 340421 & 8.9 \\
\hline & Appeals to values & 96717 & 1390501 & 7.0 \\
\hline \multirow[t]{6}{*}{ Vaccines general } & Gain & 12728 & 172174 & 7.4 \\
\hline & Descriptive & 271401 & 3684051 & 7.4 \\
\hline & Appeals to values & 19577 & 307795 & 6.4 \\
\hline & Collective & 27862 & 502341 & 5.6 \\
\hline & Emphasising reasons & 14774 & 266126 & 5.6 \\
\hline & Loss & 6307 & 130704 & 4.8 \\
\hline
\end{tabular}

they may need to be adapted to local contexts to increase their effectiveness. ${ }^{13}$ Our findings echo this recommendation. For example, some of the differences that we found between framings were consistent with existing research on effective health communications-such as gain-framed messages performing better on average than loss-framed messages in the mask and vaccine topics, both of these are 'health-affirming' behaviours as opposed to 'illnessdetecting' behaviours. ${ }^{26}$ However, across topics, countries and demographic factors, the best performing framings sometimes varied. What works best in one language or one country may not be what works best in another language or another county. Governments and global organisations such as WHO will need to consider that focusing on a particular framing might be more or less effective in different languages, countries and communities. To ensure that messages are maximally effective and do not create or exacerbate digital divides, organisations should work closely with local communities and experts to craft or adapt messages for the local context.

There are several limitations to this work. We only examined messages in the context of online search ads in English;

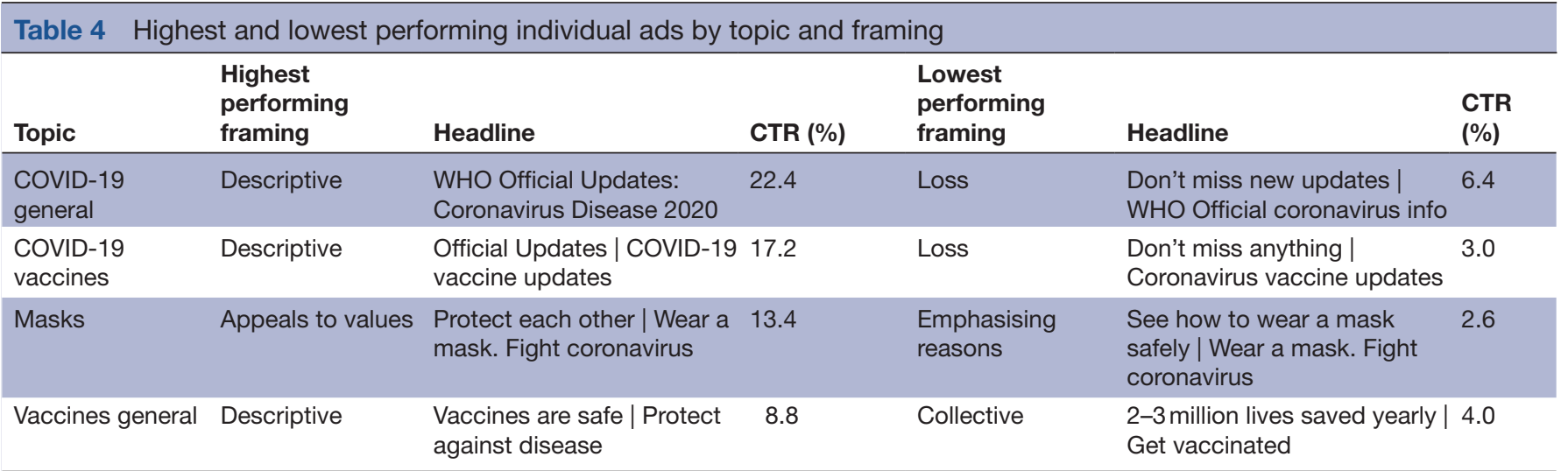

CTR, click-through rate. 
our findings may not hold in other online contexts (such as social media), offline contexts or other languages. Additionally, we only examined one outcome-whether or not users clicked on an ad (ie, CTR). There are many other important outcomes that could be examined including whether users understand the information and feel confident about how to use it. Connecting users with authoritative information is only a first step; it is crucial that the information also be accessible, understandable and actionable for a wide audience. ${ }^{30}$ To maximise the impact early on, organisations may want to initially prioritise connecting individuals to easy read, understandable and actionable information over information that is more difficult for the general public to comprehend or apply in practice.

Another important limitation is that this experiment ran for a little more than 2 months, and we examined message performance for large populations of people. The most effective messaging strategy may vary based on the stage in the pandemic as well as the information needs of different subgroups of a population. For example, highlighting the gains of receiving the COVID-19 vaccine might be a more motivating and effective message now when the vaccine is available in many countries, as compared with this experiment which ran before the vaccine was publicly available. Similarly, effective messages may differ for early adopters of COVID-19 health behaviours (eg, mask wearing, vaccination) versus late adopters or those who are hesitant. When agencies and organisations run health messaging campaigns, it would be beneficial to monitor the performance of different messaging over time and across different subgroups so that they can detect and respond to changing information needs.

There are also limitations due to Google Ads system. Because the artificial intelligence-automated system was largely self-directed, we cannot examine how multiple variables, such as the context of the user search, including the operating system, time of day and day of the week, were combined to optimise the ads. In addition, although online ads are common, executing an online ad campaign has not historically been part of public health training or practice. Therefore, it may not be feasible for some public health teams to launch and manage such a campaign. WHO and other agencies have received ad grants to undertake ad campaigns, and the cost implications may also limit replicability. However, smaller tests of shorter duration could be executed with online ad platforms and enable national or regional public health authorities to optimise messages for their own contexts. In our view, it is also important for agencies and researchers that have the resources to experiment with messaging and share their findings and insights broadly so that they can be used by others.

Historically, online public health ad campaigns were not commonly used by governments or their ministries of health. This has changed somewhat during the COVID-19 pandemic as some governments, such as Australia's, have adopted them. We believe that even more agencies could do so more often. As part of the Google Ads programme, currently 129 government agencies and other health-related organisations are receiving ad grants to disseminate timely and accurate COVID-19 messages and are applying the messaging tactics we found to be successful to design their ads. As a result of this work, many are using message framing similar to that we found to be effective and, anecdotally, are seeing increases in engagement.

Meaningful partnerships between technology companies, governments and global health agencies have the potential to advance public health. Yet, important challenges and concerns of agencies, such as WHO, exist around working with large technology companies, including that this work may go beyond the 'normative' work of the agency, that it may raise ethical concerns such as data ownership and privacy and that it may create real or perceived conflicts of interest. These are important issues that need to be considered and addressed carefully by agencies and companies before working together. In particular, it is important for collaborations to have a high degree of transparency to ensure accountability and help foster confidence in the efforts of public health agencies. If these issues are not appropriately addressed, there may be risks to public perception and trust that may negatively impact the public's willingness to follow the advice of these agencies.

For this work, we consulted with experts in health policy and ethics to ensure that the work followed standard practice for collecting and examining ad performance data and that there were no ethical concerns. All of the data are owned by WHO, and the metrics used for this work are standard metrics available to all advertisers who use Google Ads. The data are aggregated and anonymised so that no individual can be identified, the data are protected by the Ads system, no additional user data were collected and no data were used for purposes other than examining the performance of these messages. Google provided pro-bono funding for these ads and assisted in the implementation of the experimental ads but otherwise provided no data or non-public information. Discussions are ongoing within WHO to ensure that ethics continue to be managed successfully in future collaborations.

Developments in digital technology, combined with the increased demand for timely and reliable health information during the COVID-19 pandemic, provided WHO with an opportunity to develop a data-driven solution to a pressing public health issue. In doing so, WHO was able to effectively connect more people to its authoritative content than had ever been possible in the past.

\section{CONCLUSION}

WHO is successfully optimising messages as part of a public health ad campaign to increase traffic to its authoritative COVID-19 content, counter misinformation and provide reliable and timely information to those who need it. We have demonstrated that online ads hold promise for national and global health campaigns and offer practitioners a powerful tool to target the public with trustworthy information and to rapidly test and optimise messages for public health campaigns. This way of looking at messaging 
and changing framing is a major lesson that may also be applicable to other digital platforms, including social media.

Acknowledgements The authors give thanks to Karen B DeSalvo for her guidance and support. The authors would also like to thank Rachael Hinton for her editorial support on this version of the paper.

Contributors $A B P$ proposed the idea for this manuscript. $A B P, M C$ and $\mathrm{HGW}$ wrote and contributed to the first draft. MC, SM and BV conducted the data analysis for this paper. All authors reviewed the analysis, commented on drafts and approved the final version of this paper. ABP is the guarantor for this manuscript and accepts full responsibility for the work, had access to the data, and was responsible for the decision to publish.

Funding This study was funded by Google.

Competing interests $\mathrm{ABP}$ and MR are employed by WHO which received funding from Google in the form of in-kind donation of ad inventory for the WHO ad campaign. All other authors are employees of Google. MC, HC, EC, MS, BV, KO'C, HGW and SM also declare they have stock (vested and unvested) in Google. To note, HGW is no longer an employee of Google, but he was during the initial drafting of this paper.

\section{Patient consent for publication Not required.}

Ethics approval This study does not involve human participants.

Provenance and peer review Not commissioned; externally peer reviewed.

Data availability statement Data are available upon request.

Supplemental material This content has been supplied by the author(s). It has not been vetted by BMJ Publishing Group Limited (BMJ) and may not have been peer-reviewed. Any opinions or recommendations discussed are solely those of the author(s) and are not endorsed by BMJ. BMJ disclaims all liability and responsibility arising from any reliance placed on the content. Where the content includes any translated material, BMJ does not warrant the accuracy and reliability of the translations (including but not limited to local regulations, clinical guidelines, terminology, drug names and drug dosages), and is not responsible for any error and/or omissions arising from translation and adaptation or otherwise.

Open access This is an open access article distributed in accordance with the Creative Commons Attribution Non Commercial (CC BY-NC 4.0) license, which permits others to distribute, remix, adapt, build upon this work non-commercially, and license their derivative works on different terms, provided the original work is properly cited, appropriate credit is given, any changes made indicated, and the use is non-commercial. See: http://creativecommons.org/licenses/by-nc/4.0/.

\section{REFERENCES}

1 Vaccine. Google trends. Available: https://trends.google.com/trends/ explore? $\mathrm{q}=\% 2 \mathrm{Fg} \% 2 \mathrm{~F} 11 \mathrm{j} 2 \mathrm{cc}$ q llhttps $\% 20 \% 2 \mathrm{~F} \% 2 \mathrm{Ftrends}$.google com\%2Ftrends\%2Fexplore\%3Fq\%20\%2Fg\%2F11j8_9sv06,\% 2Fm\%2F07 7

2 Year in search 2020. Google trends. Available: https://trends.google. com/trends/yis/2020/GLOBAL/

3 Google trends. explore. COVID-19 vaccine. Available: https://trends. google.com/trends/explore?date=2020-01-01\%202021-08-16\&q=\% 2Fg\%2F11j8_9sv06

4 World Health Organization. Novel Coronavirus(2019-nCoV) Situation Report-13, 2020. Available: https://www.who.int/docs/defaultsource/coronaviruse/situation-reports/20200202-sitrep-13-ncov-v3. pdf

5 Pichai S. COVID-19: $\$ 800+$ million to support small businesses and crisis response, 2020. Available: https://blog.google/inside-google/ company-announcements/commitment-support-small-businessesand-crisis-response-covid-19/

6 Yom-Tov E, Muennig P, El-Sayed AM. Web-Based antismoking advertising to promote smoking cessation: a randomized controlled trial. J Med Internet Res 2016;18:e306.

7 National Collaborating Centre for Methods and Tools. Rapid review update 1: what are best practices for risk communication and strategies to mitigate risk behaviours? 2021. Available: https://www. nccmt.ca/knowledge-repositories/covid-19-rapid-evidence-service

8 Lee J-K, Bullen C, Ben Amor Y, et al. Institutional and behaviourchange interventions to support COVID-19 public health measures: a review by the Lancet Commission Task force on public health measures to suppress the pandemic. Int Health 2021;13:399-409.

9 Gallagher KM, Updegraff JA. Health message framing effects on attitudes, intentions, and behavior: a meta-analytic review. Ann Behav Med 2012;43:101-16.

10 Ghio D, Lawes-Wickwar S, Tang MY, et al. What influences people's responses to public health messages for managing risks and preventing infectious diseases? a rapid systematic review of the evidence and recommendations. BMJ Open 2021;11:e048750.

11 Yom-Tov E, Shembekar J, Barclay S, et al. The effectiveness of public health advertisements to promote health: a randomizedcontrolled trial on 794,000 participants. NPJ Digit Med 2018;1:24.

12 Penţa MA, Băban A. Message framing in vaccine communication: a systematic review of published literature. Health Commun 2018;33:299-314.

13 Wood S, Pate MA, Schulman K. Novel strategies to support global promotion of COVID-19 vaccination. BMJ Glob Health 2021;6:e006066

14 Bergström A, Ehrenberg A, Eldh AC, et al. The use of the PARIHS framework in implementation research and practice-a citation analysis of the literature. Implementation Science 2020;15:68.

15 Consensus statement prepared by the scientific pandemic influenza group on behaviours (Spi-B) for the scientific Advisory group for emergencies (SAGE), 2020. Available: https://www. gov.uk/government/publications/spi-b-consensus-on-bamecommunication-22-july-2020

16 Gantiva C, Jiménez-Leal W, Urriago-Rayo J. Framing messages to deal with the COVID-19 crisis: the role of Loss/Gain frames and content. Front Psychol 2021;12:568212.

17 Lunn PD, Timmons S, Belton CA, et al. Motivating social distancing during the COVID-19 pandemic: an online experiment. Soc Sci Med 2020;265:113478.

18 Motta M, Sylvester S, Callaghan T, et al. Encouraging COVID-19 vaccine uptake through effective health communication. Frontiers in Political Science 2021;3.

19 Wood S, Schulman K. When vaccine apathy, not Hesitancy, drives vaccine disinterest. JAMA 2021;325:2435-6.

20 Bonell C, Michie S, Reicher S, et al. Harnessing behavioural science in public health campaigns to maintain 'social distancing' in response to the COVID-19 pandemic: key principles. J Epidemiol Community Health 2020;74:617-9.

21 Wood S, Schulman K. Beyond Politics - Promoting Covid-19 Vaccination in the United States. N Engl J Med 2021;384:e23.

22 Iran: over 700 dead after drinking alcohol to cure coronavirus. Aljazeera, 2020. Available: https://www.aljazeera.com/news/2020/4/ 27/iran-over-700-dead-after-drinking-alcohol-to-cure-coronavirus

23 Porter T. A leader of a movement touting toxic bleach as a 'miracle' COVID-19 cure has been charged following a 5-year-old boy's death. Business Insider France, 2021. Available: https://www. businessinsider.fr/us/toxic-bleach-miracle-andreas-kalcker-chargedargentina-2021-9

24 Coleman A. Hundreds dead' because of Covid-19 misinformation. BBC news, 2020. Available: https://www.bbc.com/news/world53755067

25 Pew Research Centre. Majority of Americans now say they would get a vaccine for the coronavirus, 2020. Available: https://www. pewresearch.org/science/2020/12/03/intent-to-get-a-covid-19vaccine-rises-to-60-as-confidence-in-research-and-developmentprocess-increases/ps 2020-12-03 covid19-vaccine-intent 00-01/

26 Rothman AJ, Salovey P. Shaping perceptions to motivate healthy behavior: the role of message framing. Psychol Bull 1997;121:3-19.

27 Google ads help. about demographic targeting, 2021. Available: https://www.myendnoteweb.com/EndNoteWeb.html?func=new\&

28 Measuring digital development. Facts and figures. Geneva: International Telecommunication Union, 2019.

29 OECD Policy Responses to Coronavirus (COVID-19). Transparency, communication and trust : The role of public communication in responding to the wave of disinformation about the new Coronavirus, 2020. Available: https://www.oecd.org/coronavirus/ policy-responses/transparency-communication-and-trust-therole-of-public-communication-in-responding-to-the-wave-ofdisinformation-about-the-new-coronavirus-bef7ad6e/

30 Mac OA, Muscat D, Ayre J. Coronavirus (COVID-19) vaccination information must pay attention to health literacy: analysis of readability of official COVID-19 public health information. Med J Aust 2021. https://www.mja.com.au/journal/2021/coronavirus-covid-19vaccination-information-must-pay-attention-health-literacy 